\title{
Methodology of research on drivers perception at level crossings
}

\author{
Anna Kobaszyńska-Twardowska ${ }^{1,{ }^{*},}$, Marta Galant $^{1}$, Adrian Gill ${ }^{1}$, Piotr Smoczyński ${ }^{1}$, and \\ Adam Kadziński ${ }^{1}$ \\ ${ }^{1}$ Poznan University of Technology, Pl. M. Skłodowskiej-Curie 5, 60-965 Poznań, Poland
}

\begin{abstract}
The article presents a proposition of a methodology of research performed to assess car drivers' perception at level crossings. Its main assumptions as well as the description of devices and tools selected for carrying out the research were given. The steps of the proposed methodology algorithm are discussed in detail. The background of the issue presents the conditions of the functioning of railway crossings in Poland. The last part of the article are the final remarks, in which the areas of application of results obtained according to the proposed methodology are indicated.
\end{abstract}

\section{Introduction}

Level crossings are definitely the most dangerous spots at railway network, where collisions between rail and road vehicles can occur and cause significant (negative) consequences. Therefore it is understandable that people tend to take actions to keep the risk of hazards generated at these spots as low as possible. One of the issues that arise during preparation and implementation of safety management system policies is the lack of a proper risk picture. This can possibly be changed by introducing the perception assessment of road vehicle drivers, which has been getting more and more attention lately.

In spite of the growing role of robotics, automation, and other integrated technological processes, human operators are still the most important element in both facility and process control systems. The analysis of activities, sequences of actions or reaction control constitute a point of departure for research on increasing the level of safety when performing actions in the human-machine system. When level crossings are being crossed, the number of tasks performed by the driver of a road vehicle increases, and therefore, the level of their cognitive load increases as well. The effect of this cognitive overload is a decrease in the efficiency of task performance. The operator whose cognitive system is overloaded will react more slowly and skip certain information. This results in a longer reaction time and a tendency do make more mistakes, as well as in lowering the quality or efficiency of task performance, including the ability to make the right decisions. In spite of the introduction of various technical devices supporting the driver, efficiency and safety is still determined by their actions.

\footnotetext{
* Corresponding author: anna.kobaszynska-twardowska@put.poznan.pl
} 
Review of research on driver behavior on the level crossings was carried out by the authors and presented in [1,2].

The aim of the paper is to propose a research methodology to assess road vehicle (passenger car) drivers' perception of the external environment around level crossings. With the use of the available devices (e.g. driving simulator, eye tracker, EEG, pulse oximeter), activities and behaviours of road vehicle drivers when approaching and crossing level crossings can be recorded and identified. Studies of the cognitive load can be divided according to their nature into subjective, objective, behavioural, and based on transport mode indicators. The proposed research methodology therefore will be assuming a multidirectional measurement path in order to obtain a picture of the driver's psychophysical efficiency.

\section{Conditions of the functioning of level crossings in Poland}

In Poland, across about 18,000 railway lines, more than 13,000 level crossings and pedestrian level crossings are in use, where more than 200 undesirable events a year take place with the participation of railway and road vehicles. Moreover, in the area of level crossings, accidents and collisions of road vehicles are recorded. In 2016, there were 1313 collisions and 73 accidents. The definite majority of these events occurred due to the improper behaviour of road users (drivers and pedestrians) [3].

Regulation [4] allows for a division into 6 categories of level crossings and pedestrian level crossings. Qualification into the individual categories, marked with letters A-F, depends, among others, on the manner of traffic management on the road, the exposure factor (i.e. the product of two factors: the number of road vehicles crossing and the number of trains passing through the given level crossing per day), and the road category. Moreover, Regulation [4] specifies the types of active and passive (warning signs) protection possible to use with the individual level crossing categories.

Level crossings of category A and B are equipped with barrier or gate devices, category $\mathrm{C}$ level crossings are equipped with automatic traffic lights, and category D level crossings - only with warning signs. Category E includes pedestrian crossings and category $\mathrm{F}$ - nonpublic level crossings and pedestrian level crossings. Their quantity, with a division into categories, was presented in Figure 1.

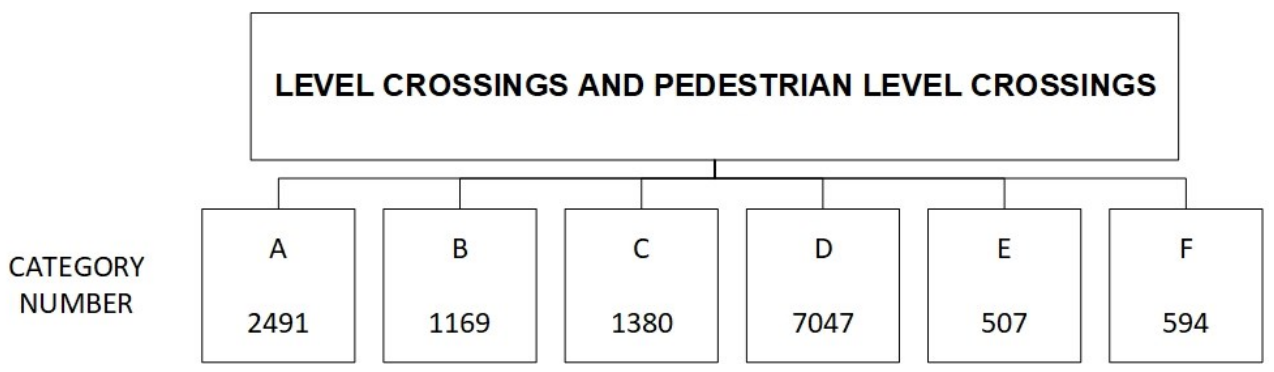

Fig. 1. The quantitative structure of level crossings and pedestrian level crossings in 2016. Source: own elaboration based on [5].

Category D level crossings constitute the largest group, equipped only with passive safety system elements (54\% of all the level crossings and pedestrian level crossings).

Level crossings are places where undesirable events (accidents, serious accidents, incidents) occur. Figure 2 presents the percentage share of undesirable events at level crossings with a division into categories, after [5].

Statistical data shows that the number of undesirable events at level crossings equipped with automatic traffic lights and half-barriers (category B and C level crossings) is over two 
times lower in percentage terms than at the level crossings equipped with passive safety features only (category D level crossings). In the undesirable events which occurred at level crossings and pedestrian crossings, seven groups of road users who participated in events involving railway vehicles can be distinguished.

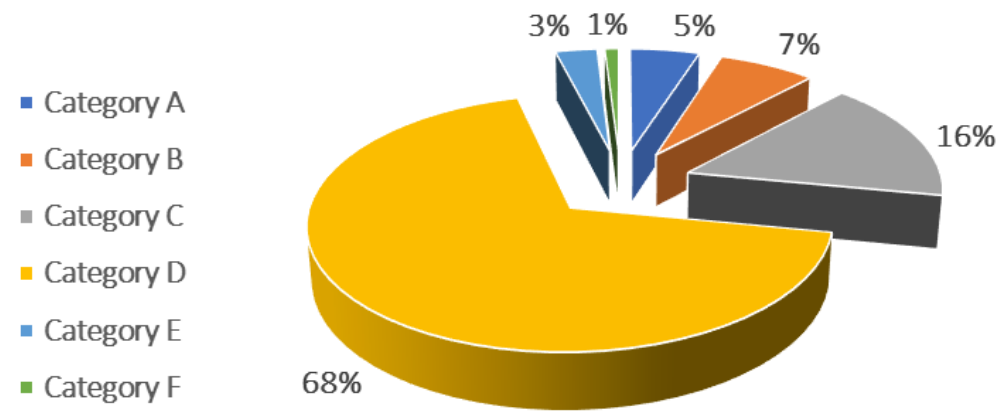

Fig. 2. The percentage share of undesirable events at level crossings and pedestrian level crossings in 2016. Source: own elaboration based on [5].

Figure 3 presents the quantitative share of the individual groups in undesirable events at level crossings involving railway vehicles [5].

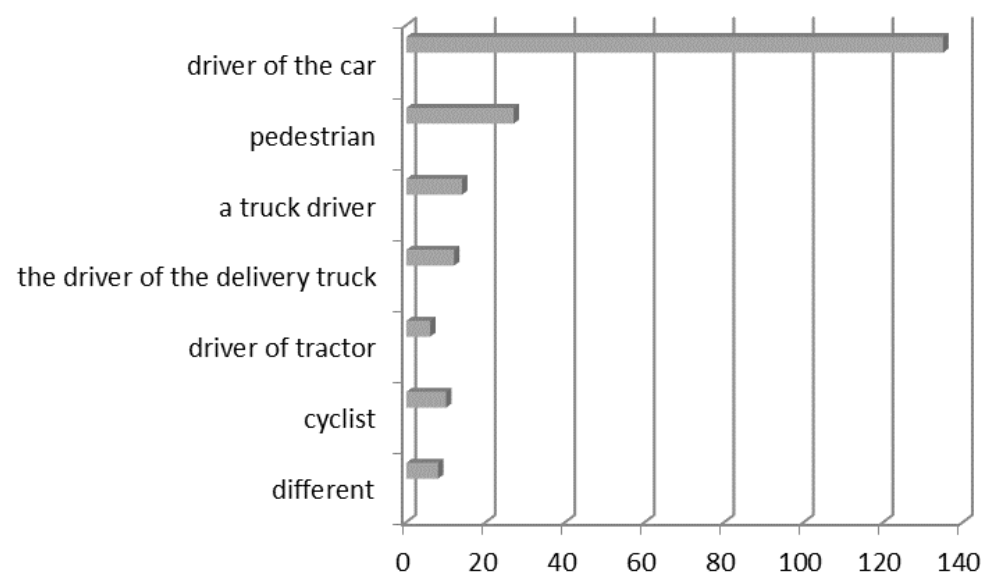

Fig. 3. The quantitative share of participants in undesirable events at level crossings in 2016. Source: own elaboration based on [5].

The largest group of participants of undesirable events at level crossings involving railway vehicles are drivers of passenger cars. Undesirable events at level crossings may cause losses [6]. The losses may be expressed in the number of fatalities and injuries. In 2016, 48 fatalities and 39 severely injured accident victims were recorded [5]. The losses generated at level crossings may also be expressed as the costs incurred by the participants of the undesirable events (both railway companies and the road-side users of level crossings). Undesirable events at level crossings also cause organisational problems resulting from resumptions of railway and road traffic and the need to replace damaged rolling stock with rolling stock fit for the performance of the transport function [7]. 


\section{Proposition of the research methodology}

\subsection{Main assumptions}

The development of simulation techniques and the increase in the efficiency of computers and systems for image generation made it possible to build virtual environments for testing and training drivers - driving simulators [8]. Their use increases the independence of the tests carried out of weather conditions and favours the repeatability of the conditions in which they are carried out. Their considerable advantage is the possibility to stage the situation of hazard to traffic safety, e.g. with the vehicle stuck at the level crossing.

The undeniable advantage of using simulators in scientific research is the opportunity to control as many factors as possible and record a number of variables, including the operator's physiological parameters and psychological state [9-11]. The use of simulators makes it possible to conduct studies that enable us to achieve complete standardisation of testing conditions [12]. The repeatability of the scenarios makes it possible to compare the behaviour of various operators in the same situation or the same operator in different situations, which is not possible in actual traffic conditions.

Proposed methodology is based on testing of the general psychophysical condition of the driver while driving within various configurations of level crossings. Driver perception parameters, such as eyeball movements, brain activity, pulse, and blood oxygenation or the galvanic skin response (GSR) are planned to be monitored. Moreover, before and after the study tests, we recommend that reaction time measurements should be made (with the use of the Piórkowski apparatus) along with the measurements of postural stability and balance (with the use of a two-platform posturograph). Study tests can be complemented by tests checking the occurrence of the symptoms of the simulator sickness (with the use of the SSQ - simulator sickness questionnaire).

Before entering the study, the participants should complete detailed questionnaires. Information contained in the survey can be: driver's age, sex, experience (expressed in the number of kilometres covered each year), simulator sickness, and experience with the use of driving simulators and similar devices. Moreover, the questions can also concern the use of other modes of transport (e.g. plane, ship), medical history, medicines taken, alcohol consumption or sleep duration before participation in the tests.

A precondition for the given person to be qualified to take part in the tests as a driver is that they have to hold a category B driving licence. The ability to drive a passenger car is necessary for the subject to perform all the activities naturally (in the case of people without a driving licence, we could possibly observe too much focus on learning the given activity or an increased level of stress caused by the new experience - this could render the results unreliable).

The driver's age and experience plays a significant role in the perception of hazards. The driver may react in a very individual way e.g. when approaching a level crossing and the warning signs informing about the approaching train, as well as to the train approaching. Apart from the change in the perception of hazards, a change in the perception of external stimuli is also possible. Therefore, the tests should be conducted in age groups, e.g. age of 20-30, 30-50 and over 50 .

The methodology is built on the following five steps:

1. Preliminary studies qualifying the selected factors for further research.

2. Analysis of the influence of changing the road parameters on the psychophysical condition of the driver. 
3. Tests of the influence of the occurrence of a level crossing on the psychophysical condition of the driver along with the implementation of selected scenarios in the simulator environment.

4. Synthesis of the data obtained from the simulator tests.

5. Verification tests in actual traffic conditions.

\subsection{Devices and testing tools}

The primary device used for the research is the car driving simulator (e.g. AS-1200S, which is part of the testing equipment of the Institute of Combustion Engines and Transport, Poznan University of Technology). The simulator was constructed based on an actual, fullsize cabin of the Lancia Ypsilon. The use of a real vehicle makes it possible to accurately reconstruct the driver's work space, taking into consideration its ergonomics and the road vehicle driver's sensations as similar as possible to the actual ones.

The cabin was installed on a hexapod, which made it possible to obtain a system with six degrees of freedom. Additionally, the device is equipped with a spherical screen with projectors enabling the visualisation of a 220-degree field of view (FoV), which means that while driving, the driver does not see the edge of the screen, but the computer-generated scenery (trees, buildings, elements of road infrastructure, people, etc.) moving at the given speed. This type of visualisation makes it possible to recreate the conditions so similar to the actual ones that the subject has the impression of driving an actual car. The visual quality is provided thanks to the image refresh rate of $60 \mathrm{~Hz}$ in the normal mode. With a very high load (density of traffic and extensive visualisation), the minimum rate is $30 \mathrm{~Hz}$. The delay control reaction occurs in less than $50 \mathrm{~ms}$, the mobile platform delay is lower than $10 \mathrm{~ms}$.

The simulator also generates mechanical stimuli (cabin and driver seat vibration) and sound effects (a four-channel sound system inside the cabin), enhancing the effect of actual driving. The driving parameter recorder enables the recording of data such as acceleration, pedal position (acceleration, brake, and clutch), position of the gear lever, steering wheel, traffic indicators, the use of the horn and hand brake during the simulation. The manufacturer of the device provided software enabling control of the time settings, weather conditions (fog, rain, snow, wind), the manner of driving (type of transmission, pedal position), car type, and elements of training scenarios.

Tests with the use of the following testing tools are planned:

- eye tracker - used to measure eye movements during the simulator drive;

- electroencephalograph (EEG) - a non-invasive method of neuroimaging, enabling the recording of the measurement of the voltage resulting from brain activity;

- pulse oximeter - the device makes it possible to measure the subject's vital signs, such as the pulse (the number of heart beats per minute) or saturation $\left(\mathrm{SpO}_{2}\right.$, determining the level of the patient's blood oxygenation, i.e. the level of haemoglobin saturation with oxygen). The pulse level is closely connected with the stress experienced by the subject; it is assumed that the sudden appearance of a train at the crossing or the sole occurrence of the crossing itself may cause the subjects' pulse to rise,

- two-platform posturograph - a device used to measure the stability of body posture and the subject's balance; posturographic tests will be carried out before and after the drive, both with the eyes open and closed. This will enable us to determine whether and how the simulator test influenced the subject,

- Piórkowski apparatus - a device used to test the visual-motor coordination and precision of movement; a test of the speed of a psychomotor reaction to simple light stimuli emitted at a rate imposed by the machine, 
- galvanic skin response - the test consists in the use of the phenomenon of the body's resistance to the flow of electric current and the ability to quickly react to threat factors; the measurement of the value of the skin's electric resistance dependent on the level of the skin's moisture resulting from the work of the sweat glands; research work has shown that the GSR level increases with the increase of the subject's cognitive load,

- simulator sickness questionnaire (SSQ) - used to identify the symptoms of the simulator sickness experienced by the subject, occurring at the given moment (i.e. before, during, and after simulator tests).

It is worth noticing that in spite of the fact that the phenomenon of simulator sickness is well-known, its occurrence with reference to the other psychophysical parameters has never been studied. A comparative analysis of the two results may reveal interesting, previously unknown dependencies, which will allow to introduce activities aimed at limiting the negative symptoms of this sickness in the future.

\subsection{Description of the methodology steps}

The execution of the first step is done through preliminary studies qualifying the selected factors for further research. The implementation of its assumptions is essential for the correct execution of further work.

After determining the validity of the applied techniques, the second step of the methodology, i.e. the analysis of the influence of changing the road parameters on the psychophysical condition of the driver, begins. At this stage it will be able to find the basic dependencies between the change of the selected parameters and the driver's psychophysical condition. Changes such as time of day (natural lighting of the road), artificial lighting (street lamps), weather conditions (change in the grip caused by rainfall/snowfall), the occurrence of wind, and obstacles will be analysed.

The accumulated conclusions from the tests at steps 1 and 2 will make it possible to carry out the primary tests, i.e. the step 3 . Conducting the tests require the implementation of selected scenarios in the simulator environment, for example:

- level crossings intersecting with the road at various angles,

- various configurations of road signs, in varying technical condition,

- wooded/urban area - with buildings limiting visibility and without them,

- level crossings in hollows and on hills,

- one level crossing with traffic lights permanently on,

- the reaction of the road vehicle driver to the train approaching (linked with the indications of the signalling system),

- various visual configurations of railway vehicles: passenger trains, cargo trains, rail trolleys - in different colours,

- train sound signal (automatic or triggered by the operator of the simulator).

Tests should be divided into three stages:

I - immobile motion platform, day, good visibility conditions,

II - mobile motion platform, day, good visibility conditions,

III - mobile motion platform, dawn/dusk, limited visibility.

Testing of the given driver can be considered as complete, conducted correctly, and completed if the driver has taken part in all three stages of testing. Should be to use the randomisation principle, i.e. change the order of the individual stages so as to avoid the influence of the order of task performance of the measurement results.

Three time brackets were distinguished during the tests: before the drive, during the drive, and after the drive. Each test will follow the fixed measurement performance pattern, in accordance with Table 1. 
Table 1. The order of measurements during drives.

\begin{tabular}{|c|c|c|c|}
\hline Tool & before drive & during drive & after drive \\
\hline eye tracker & no & yes & no \\
\hline electroencephalograph (EEG) & no & yes & no \\
\hline simulator sickness questionnaire (SSQ) & yes & $\begin{array}{c}\text { yes, every } 5 \\
\text { minutes }\end{array}$ & yes \\
\hline pulse oximeter & no & yes & no \\
\hline two-platform posturograph & yes & no & yes \\
\hline Piórkowski apparatus & yes & no & yes \\
\hline galvanic skin response & no & yes & no \\
\hline
\end{tabular}

The full spectrum of measurements and results obtained during the tests with the use of the car driving simulator can form the basis for realisation step 5 verification tests in actual traffic conditions. At this stage, actual level crossings located within the area of the Poznan agglomeration should be selected. The verification tests will use the same testing tools as the primary studies.

\section{Final remarks}

The proposed research methodology assumes a multidirectional measurement path in order to obtain a picture of the driver's psychophysical efficiency and should allow to achieve the results which will be the basis for analyzing:

- the influence of changing the road parameters on the psychophysical condition of the road vehicle driver,

- the vehicle drivers' reaction to passive and active elements of safety systems,

- identification of hazard sources coming from road users or unrelated to road users,

- the influence of the configuration of level crossings on the perception of hazards by vehicle drivers,

- the influence of the elements of level crossing infrastructure on the level of safety in road traffic,

- the influence of the road vehicle drivers' age on their perceptual abilities when driving a vehicle,

- the influence of the road vehicle drivers' experience on their perception of hazards generated at level crossings,

- the influence of the area's topography on the level of safety at level crossings

- road vehicle drivers' behaviour directly after noticing the train and its influence on further events,

- the influence of noticing the train at the first level crossing on the behaviour at subsequent level crossings.

With the use of the available devices (e.g. driving simulator, eye tracker, EEG, pulse oximeter), activities and behaviours of road vehicle drivers when approaching and crossing level crossings can be recorded and identified. Studies of the cognitive load can be divided according to their nature into subjective, objective, behavioural, and based on transport 
mode indicators. The proposed methodology compare monitored parameters with the use of all the four methods.

Improving the safety at passive rail crossings is an ongoing issue worldwide. These crossings have no active warning systems to assist drivers decision-making and are completely reliant on the road user perceiving the approach of a train to decide whether to enter a crossing or not. Studies of road vehicle drivers' perception may help point out important elements in the surroundings of level crossings which should be the object of special attention. The expected results of the analyses of the conducted tests will increase the level of knowledge on the causes of undesirable events at level crossings. They will help to better understand the environment that level crossings form through the perception, organisation, and interpretation of the impressions of road vehicle.

The research work financed with the means of statutory activities of Faculty of Machines and Transport, Poznan University of Technology, No. 05/52/DSPB/0280.

\section{References}

1. A. Kobaszyńska-Twardowska, P. Smoczyński, A. Gill, A. Kadziński, Overview of safety systems on level crossings crossings, Autobusy, Tech. Eksploat. Syst. Transp. 12 pp. 236-239 (2017)

2. P. Smoczyński, A. Kobaszyńska-Twardowska, A. Gill, A. Kadziński, Review of research on driver behavior on the level crossings, Autobusy, Tech. Eksploat. Syst. Transp. 12 pp. 419-422 (2017)

3. System Accident and Collision Record - data for 2016, www.sewik.pl, (2017)

4. Regulation of the Minister on the technical conditions for level crossings (Dz.U. 2017 No. 234, in Polish) (2017)

5. Office of Rail Transport, Report on the railway traffic safety in 2016 in Poland (2017)

6. K. Jamroz, K. Chruzik, L. Gucma, A. Kadziński, J. Skorupski, A. Szymanek, Analiza możliwości integracji metod zarządzania ryzykiem, in: Zintegr. Syst. Bezpieczeństwa Transp. 2 Tom, Uwarunk. Rozw. Integr. Syst. Bezpieczeństwa Transp. (in Polish), (Politechnika Gdańska \& WKŁ, Warsaw, 2009)

7. A. Kobaszyńska-Twardowska, Risk management at level crossings. PhD dissertation, Poznan University of Technology, 2017

8. Z. Lozia, Practical aspects of driving simulator applications, Postępy Nauk. i Tech. 14 pp. 148-156 (2012)

9. J. Merkisz, J. Markowski, P. Fuć, M. Galant, Review of methods of measuring the operator overwork in research using a driving simulator, Logistyka. 3 pp. 3188-3194 (2015)

10. M. Niezgoda, T. Kamiski, M. Uciska, M. Kruszewski, Effective methods for drivers research with use of a driving simulator, J. KONES Powertrain Transp. 18 (2011)

11. C.J.D. Patten, Cognitive workload and the driver: understanding the effects of cognitive workload on driving from a human information processing perspective (Department of Psychology, Stockholm University, 2007)

12. M. Galant, J. Merkisz, Analysis of the possibilities of using EEG in assessing pilots' psychophysical condition, Sci. J. Silesian Univ. Technol. Ser. Transp. 95 pp. 39-46 (2017) 